ФИЛОСОФИя

DOI: 10.17805/trudy.2018.2.1

\title{
ФИЛОСОФИЯ КАК САМОСОЗНАНИЕ СВОБОДЫ
}

\author{
B. М. Межуев \\ Институт философии РАН
}

Аннотация: В статье анализируется основная функция философии - самосознание человека. Текст доклада автора на Всероссийской научной конференции «Культура между Логосом и Мифом: к проблеме бессознательного (к 80-летию А. Э. Воскобойникова)», которая прошла в Московском гуманитарном университете 26-27 октября 2017 года.

Ключевые слова: философия; история философии; свобода; самосознание

\section{PHILOSOPHY AS SELF-AWARENESS OF FREEDOM}

\section{M. Mezhuev}

Institute of Philosophy, Russian Academy of Sciences

Abstract: The paper analyses the primary function of philosophy - human selfawareness. The text of the author's speech at the All-Russian Scientific Conference "Culture between Logos and Myth: on the Issue of the Unconscious (dedicated to the 80th anniversary of A. E. Voskoboynikov)", which was held at Moscow University for the Humanities on 26-27 October 2017.

Keywords: philosophy; history of philosophy; freedom; self-awareness

В составе европейской культуры философия с момента своего зарождения выполняла функцию не просто знания человека о мире, но его самосознания, т. е. знания о самом себе, о том, что образует сущность его бытия. Наличие самосознания - главное, что отличает человека от всех других живых существ. В «Феноменологии духа» (подраздел А главы IV) Гегель выразил эту мысль со всей возможной четкостью. Вот как она звучит в пересказе Александра Кожева: «Человек - это Самосознание. Он сознает себя, сознает, что он - человек, что в бытии человека заключено его человеческое достоинство и что этим-то он и отличается от животного, которому выше простого Самоошущения не подняться. Человек осознает себя в тот миг, когда - «впервые» - говорит: «Я». Понять человека, поняв его 
Научные труды Московского гуманитарного университета 2018 № 2

происхождение, - значит понять, откуда берется это раскрывшееся в слове Я» (Кожев, 2003: 9).

Разумеется, не только философия брала на себя функцию самосознания. Ту же функцию выполняли миф, религия, искусство. Но уже в античности человек, выходя из-под власти мифа, осознавал себя принадлежащим к «царству логоса», в котором мир представал для него не как место обитания богов, добрых или злых духов, а как порождение материальных или идеальных субстанций, отражающих ему его собственное бытие в этом мире.

Переход от мифа к логосу стал следствием возникновения греческого полиса. По словам Ж.-П. Вернана, «становление полиса, рождение философии - весьма тесные связи между этими явлениями объясняют возникновение рациональной мысли, истоки которой восходят к социальным структурам и складу мышления, присущим греческому полису» (Вернан, 1998: 156). Греческий разум «во всех своих достоинствах и недостатках - ...дитя полиса» (там же: 159). Полис - первая в истории форма демократии, т. е. власти не тиранов и деспотов, а самих граждан полиса, каждый из которых осознает себя свободным существом. В противоположность мифу философия и стала для них формой осознания мира и самих себя. Ее можно определить поэтому как самосознание человека в свободе - духовной и политической, или просто как самосознание свободы. Начиная с античности, расцвет философской мысли падает именно на те периоды европейской истории, которые отмечены переходом от единоличной власти царствующих монархов к той или иной форме демократии. Это, во-первых, Античность, во-вторых, Новое время.

Жизнь по законам, установленным волей и разумом самих граждан, рождала уверенность в столь же разумном устроении и всего остального мира. Если люди способны руководствоваться в своей жизни собственным разумом, почему бы и миру не быть столь же разумным, существовать не по воле богов, а по собственным законам. Греческий полис, опрокинутый на все мироздание, рождал идею космоса - вечного и неизменного порядка вещей, открывающегося человеку посредством философского сознания. В этом порядке человеку светила не столько природа самих вещей, сколько его собственная природа, как она давала знать о себе в мире полиса.

С момента своего возникновения философия стремилась придать самосознанию логически доказательную форму научного знания, которая, однако, в отличие от эмпирических, опытных наук базируется на сверхчувственных (трансцендентальных) доводах самого разума. В таком качестве она и получила в Средние века название метафизики - «первой науки» среди всех остальных. В наиболее систематизированном виде процесс возвышения самосознания до уровня научного знания, даже знания абсолютного, 
был представлен в «Феноменологии духа» Гегеля, которого поэтому многие сочли последним философом в истории философской мысли. Назову только два имени - Карл Маркс и Огюст Конт. Оба думали, что никакая другая философия после Гегеля невозможна и потому она должна уступить свое место науке - согласно Марксу, исторической науке, названной им материалистическим пониманием истории, согласно Конту, социальной науке, или социологии.

Хотя вопреки всем этим предсказаниям, философия и после Гегеля продолжала существовать, пусть и в иной - постклассической - форме, вопрос о ее значении и необходимости для современного человека с тех пор уже не сходит с повестки дня. О несовременности, или «несвоевременности», философии писал Ницше, провозгласив своим кредо нигилизм - тотальное отрицание всего, во что верили философы, начиная с Сократа, Платона и Аристотеля. По словам Ницше, философия, если и была нужна кому-то, то только грекам, создавшим ее, да и у них она не всегда служила признаком здоровья и силы. Такой она была только у досократиков, тогда как, начиная с Сократа, все ее мыслепорождения свидетельствуют лишь об упадке и разложении греческого духа, его отрыве от жизни, омертвлении. Культурную задачу философии, писал Ницше, нельзя угадать и понять в современных условиях, потому что здесь нет такой культуры. «Только культура, подобная греческой, может ответить на вопрос о задачах философии; только она может вообще оправдать философию, ибо она одна знает и может доказать, почему и каким образом философ не есть случайный странник, то сюда, то туда забредший» (Ницше, 1994: 197). Если у греков философия — «главная звезда в солнечной системе культуры» (там же), то в современном мире философия «нежданная и наводящая ужас комета» (там же), непонятно зачем залетевшая в нашу систему.

Столь же критичен в оценке современной философии и Освальд Шпенглер. Сравнивая в «Закате Европы» современных философов с мыслителями прошлого, он пишет: «Становится стыдно, когда переводишь взгляд с людей такого калибра на сегодняшних философов. Какая ничтожность во всем личном! Какая заурядность политического и практического горизонта!... Тщетно оглядываюсь я вокруг, ища среди них кого-то, кто составил бы себе имя хотя бы одним глубоким и опережающим суждением по какому-либо решающему злободневному вопросу. Сплошь и рядом наталкиваюсь я на провинциальные мнения, каковые можно услышать от кого угодно» (Шпенглер, 1993: 178-179). И далее: «Очевидно, упущен из виду последний смысл философской активности. Ее путают с проповедью, агитацией, фельетоном или специальной наукой. От перспективы, открывающейся с высоты птичьего полета, опустились до лягушачьей перспективы. Ситуация упирается 
Научные труды Московского гуманитарного университета 2018 № 2

ни больше ни меньше как в вопрос: возможна ли вообще сегодня или завтра подлинная философия?» (там же: 179). Систематическая философия, охватывающая все мироздание, явно закончилась, завершилась и этическая философия. Осталось лишь сопоставлять между собой разные культурные миры, используя метод сравнительной исторической морфологии. Это позиция скептицизма, отрицающая любой универсализм и наличие вечных истин, провозглашающая относительность любого суждения о мире. Скептицизм отрицает и возможность существования философии как законченной системы. И только «историю философии», заключает Шпенглер, он принимает «как последнюю серьезную тему философии. Это и есть скепсис» (там же: 182).

Сошлюсь также на мнение Хайдеггера, высказанное им в беседе с французскими корреспондентами в 1969 году. На замечание первых о том, что «сегодня кризис университетов сопровождается недоверием к самому смыслу философии. Для большинства она не имеет права на существование, она стала бесполезной», Хайдеггер ответил: «Это как раз то, о чем я всегда думал»; «Философия несвоевременна по своей сущности, ибо она принадлежит к тем редким явлениям, судьба которых в том и состоит, что они не могут встретить непосредственный отклик» (Хайдеггер, 1991: 146). Философия «одна из редких возможностей автономного и творческого существования» (там же). Смысл вопроса, на который отвечает философия, сегодня, по словам Хайдеггера, «никого не тревожит», хотя сама его постановка и многочисленные попытки ответить на него создали западную культуру.

Как бы не оценивать значение философии для современности, она, как уже говорилось, продолжает существовать в форме, весьма далекой от ее классических образцов. И, пожалуй, главной особенностью этой философии в отличие от классики является ее нежелание считать себя наукой - даже той, на какую претендовала предшествующая ей метафизика. Философию того же Ницше или Хайдеггера (равно как «философию жизни», экзистенциализм, постмодернизм, религиозную философию и пр.) трудно назвать наукой. Между философией и наукой образовалась как бы глубокая трещина, разделившая то, что можно назвать также самосознанием и знанием.

С различением самосознания и знания согласятся сегодня, видимо, многие. Труднее понять, в чем состоит это различие. Оно станет очевидным в результате возникших в конце XIX в. так называемых «наук о культуре» (по другой терминологии, «наук о духе»), охвативших собой все внеприродное пространство истории и культуры, до того считавшееся предметом исключительно философской рефлексии. Но когда и это пространство оказалось в ведении конкретных наук, пусть со своей особой методологией и логикой, отличающейся от логики «наук о природе», философия, подобно королю 
Лиру, раздавшему все свои владения детям, оказалась перед вопросом где теперь ее царство? Не обречена ли она быть теперь всего лишь «служанкой науки» (подобно тому, как была когда-то «служанкой богословия»), т. е. всего лишь логикой, гносеологией, эпистемологией научного познания, или просто «философией науки»? На этом настаивали все неопозитивисты и представители аналитической философии, объявившие метафизику, т. е. философию в ее классическом понимании, занятием, лишенным какого-либо научного смысла. С возникновением «наук о культуре» перед философией встал вопрос о ее собственном месте в системе культуры, т. е. о том, что именно отличает ее не только от мифа и религии, но и от самой науки. Может ли наука заменить ее в функции не только знания человека о мире, но и его самосознания? Не ответив на этот вопрос, нельзя понять, чем постклассическая философия отличается от классической.

Само возникновение «наук о культуре» стало возможным благодаря открытию множества культур, покончившему с представлением о ее существовании в единственном числе, т. е. как только европейской. Нет одной культуры на всех, культур много. Об этом знает сегодня каждый школьник, но из этого не всегда делают все необходимые выводы. В ситуации существования разных культур перед каждым из нас встает вопрос: какую из них и на каком основании мы считаем своей? Ведь не так просто ответить на него, зная, что культур много. Связь с собственной культурой никому не гарантирована чисто биологически - в силу текущей в нас крови или заложенных генов. Можно быть русским по крови и не быть им по культуре, равно как и наоборот. Такая связь не исчерпывается и тем, что мы знаем о культуре: можно знать ислам и не быть мусульманином. Можно быть специалистом по китайской культуре, но принадлежать к совершенно другой культуре. Знать культуру и быть в ней - разные вещи. В этой ситуации рушится формула Декарта «cogito ergo sum»: знание и бытие расходятся между собой. Знание о культуре делает нас учеными, но ничего еще не говорит о нашей собственной принадлежности к определенной культуре. Но как еще мы можем удостовериться в этой принадлежности?

По высказанному когда-то мнению Д. С. Лихачева, человек связан с культурой посредством памяти: что сохраняется в его памяти, то и есть его культура. Но только ли память связывает нас с ней? А как быть тогда с нашими надеждами, целями, планами, идеалами, даже фантазиями, т. е. с тем, что связывает нас не с прошлым, а с будущим? Живя в настоящем, трудно ограничиться одним прошлым - в нем многое приходится переосмысливать, создавать заново, от чего-то отказываться, а что-то заимствовать у других народов. Связь с собственной культурой обеспечивается, следовательно, не только памятью, но и воображением. Вопрос о «своей культуре» 
Научные труды Московского гуманитарного университета 2018 № 2

потому всегда новый вопрос, который каждое новое поколение будет решать по-своему.

Важнейшим признаком «своей культуры», конечно, является язык, на котором мы говорим и мыслим. Существуют, однако, разные культуры, которые говорят на одном языке (португальская, испанская и латиноамериканские, американская и английская), и культура, которая говорит на разных языках (индийская, еврейская). Народы, живущие в России и говорящие по-русски, не обязательно считают своей русскую культуру. В современном мире языком межнационального общения является английский язык, но отсюда не следует, что все, говорящие по-английски, принадлежат к английской культуре. Язык - важный элемент «своей культуры», но все же не исчерпывает ее целиком.

В культуре, которую мы считаем «своей», многое, конечно, зависит от нашего происхождения, воспитания, окружения, но ведь многое зависит и от нас самих, от того, что мы сами посчитаем для себя важным и ценным. В культуре, доставшейся нам от предков, нас может что-то не устраивать, вызывать отторжение, тогда как в культуре других народов мы можем находить для себя нечто важное и полезное. Граница между своей и чужими культурами задается, следовательно, не только силой внешней необходимости, предписывающей нам с непреложностью природного закона определенную культурную нишу (чем бы мы тогда отличались от бабочек в гербарии), но и нашим свободным выбором. Ее не всегда легко распознать, но именно она отделяет в культуре то, что подлежит научному изучению, от того, что требует философской рефлексии. Если наука дает нам знание о разных культурах, сколько их есть на свете,то философия отвечает на вопрос, кто я сам по культуре. Тем самым в отличие от науки философия предстает как культурное самосознание индивида, формирующееся под воздействием не внешней необходимости, а свободного выбора им своей культурной идентичности. Философия и есть форма осознания человеком сделанного им свободного выбора. И нет науки, которая смогла бы заменить философию в этой функции.

В составе европейской культуры философия как бы располагается посредине между религией и наукой (потому ее и тянет то в одну, то в другую стороны: наряду с научной существует религиозная философия). Но если религия призвана сделать людей добрыми (т. е. морально ответственными перед Богом), а наука - сильными, вооружив их знаниями и технологиями, то философия видит свою задачу в том, чтобы сделать их свободными. Философия критична в отношении как религии, так и науки - критична не в смысле их отрицания, а в смысле установления границ их компетентности, признания их относительной ценности по сравнению с человеческой сво- 
бодой, без чего религия и наука могут в равной стеиени стать смертельно опасными для человека.

Присущая человеку свобода есть главное открытие философии, сделавшее возможным и само ее появление. В разные времена философы по-разному понимали свободу, но в любом случае именно в ней усматривали главное отличие человека от всех других живых существ. Впервые сам факт существования человеческой свободы был осознан греками. Свобода для них - все то, что существует (действует, движется) в силу собственной внутренней причины, что обладает свойством самодетерминации («сausa sui» - причины самой себя) и, следовательно, имеет значение всепорождающей субстанции. Свобода - синоним всего, что неподвластно времени, на чем лежит печать вечности в противоположность тому, что существует во времени и обречено на гибель и исчезновение. Кому из смертных доступна такая свобода? Видимо, лишь тем, кто так или иначе способен соприкоснуться с вечностью. Она открывается не любому, а избранным - тем, кто может мыслить и действовать независимо от повседневных трудов и забот о своем физическом выживании и продолжении рода. Свобода есть удел тех, кто ради истины и красоты способен «пренебречь земною пользой»1․

Таким для греков был прежде всего сам философ, живущий в мире вечных истин. Но свобода философа ограничена одним лишь созерцанием, не распространяется на практические дела и поступки. Тех, кто способен не только мыслить, но и действовать в свободе, побуждаемый заботой не о личной пользе, а об общем благе, греки называли политиками. К философу и политику Аристотель добавит художника, способного бескорыстно наслаждаться чувственной красотой, неподвластной времени. Все три являют примерз жизни свободного человека, не зависящего от жизненной нужды и ею созданных обстоятельств. Им противостоят те, кто занят полезным трудом - либо по собственной воле (земледельцы и ремесленники), либо по принуждению (рабы и домашние слуги) ${ }^{2}$.

\footnotetext{
1 «Свобода, - по словам 3. Баумана, - родилась как привилегия и с тех пор всегда ею оставалась. Свобода делит и разделяет. Она отделяет лучших от остальных. Свою привлекательность она черпает из различия: ее наличие или отсутствие отражает, отмечает и обосновывает контраст между высоким и низким, хорошим и плохим, желанным и отталкивающим» (Бауман, 2006: 22).

${ }^{2}$ Как пишет Х. Арендт, «поскольку речь шла (у Аристотеля. - В. М.) об образе жизни свободы, отсекались все профессии, прислуживающие самой жизни, стало быть прежде всего труд, который как образ жизни страдал от двойной вынужденности, а именно от жизненной нужды и от приказа господина; но и созидательный образ жизни свободного ремесленника и нацеленная на прибыль жизнь торговца также оставалась вне рассмотрения. Исключались тем самым все образы жизни, которые вольно или невольно, временно или в продолжение всего срока жизни не давали свободы движения и действия,
} 
Научные труды Московского гуманитарного университета 2018 № 2

Хорошо известная грекам, но не очень ценимая ими способность трудиться (обрабатывать землю, создавать изделия ремесла, торговать, вести домашнее хозяйство), есть проявление не свободы человека, а его зависимости от собственного - смертного - тела, от своих чувственных желаний и потребностей. В этом смысле труд - обязанность не свободных граждан полиса, а преимущественно рабов и женшин. «В греческом понимании, отмечает Ханна Арендт, - ни труд, ни созидание (изготовление) вообще не могли сформировать... образ жизни, достойный свободного человека и показывающий его свободу; служа добыванию необходимого и производству полезного, они оставались несвободны, а именно продиктованы нуждами и желаниями людей» (Арендт, 2000: 20). Время «полиса» тем и отличается от времени «ойкоса» (хозяйственной жизни), что позволяет человеку заполнить его делами и поступками, способными обессмертить его имя, прославить в веках, сохранить в памяти потомков. Это время не физически конечной, а вечной жизни, пусть только духовно вечной, но способной продолжиться в новых поколениях. Оно позволяет человеку жить если не вечно, то в вечности, причем не только на том, но и на этом свете.

Оставаясь физически конечным существом, человек способен прорваться в вечность, как-то возвыситься над временем своей «быстротекущей жизни». Он живет как бы в двух мирах — чувственно воспринимаемом и сверхчувственном, который Платон, как известно, назвал миром идей ${ }^{1}$. А вот над идеями время не властно: они существуют изначально и доступны человеку лишь в акте их философского созерцания. Мышление как бы образует «дырку» во времени, сквозь которую он проникает в царство вечных истин. Человек - единственное живое существо, способное совмещать в своем бытии время и вечность: как природное, чувственное существо он живет во времени, как разумное, мыслящее - в вечностиㄴ. Способность в своих мыслях и делах жить в вечности греки и называли свободой.

не во всякий момент жизни позволяли человеку быть господином своего времени и своего местопребывания» (Арендт, 2000: 20).

1 «Платон впервые в истории философской мысли попытался дать метафизическое обоснование понятия времени, сопоставив его с вневременной вечностью» (Гайденко, 2006: 25).

${ }^{2}$ Вот как ту же мысль формулирует современный социолог: «Осознание неизбежности смерти могло бы с легкостью лишить нашу жизнь ее ценности, если бы понимание хрупкости и конечности жизни не наделяло колоссальной ценностью долговечность и бесконечность». И далее: «Осознание мимолетности жизни делает ценной только вечную длительность. Она утверждает ценность нашей жизни косвенно, порождая понимание того, что сколь бы коротка не была наша жизнь, промежуток времени между рождением и смертью - наш единственный шанс постичь трансцендентное, обрести опору в вечности» (Бауман, 2002: 300). 
С приходом христианства меняется и отношение к свободе - она перестает мыслиться как привилегия для немногих и осознается как свобода воли, дарованная Богом каждому человеку. Но дана она человеку с единственной целью - чтобы он своими добрыми делами и поступками мог искупить проклятие первородного греха и тем самым стать угодным Богу, причем не по внешнему принуждению, а в силу своей доброй воли, т. е. добровольно. В глазах верующего свобода оправдана как только сочетание добра и воли, в ином случае она - источник своеволия и греха, подпадение под власть Сатаны. В средневековой теологии свобода воли бессильна без божественной благодати и церковного благословения. Стремясь привести человеческую волю в согласие с божественной, средневековые теологи неизменно утверждали приоритет второй перед первой. Царство свободы это царство вечной жизни на том свете, в граде Небесном, и попасть туда можно лишь путем полного подчинения своей воли воле Божьей. Свобода, угодная Богу, есть свобода во имя спасения души, что никак не освобождает человека от власти земных правителей. Такая свобода не имеет ничего общего с политической и гражданской свободой. В этой ситуации философии как самосознание свободы оправдана лишь как «служанка богословия», ставящего в свою очередь человеческую свободу на службу Богу.

В эпоху Возрождения свобода будет осознана как необходимое условие уже не только небесной, но и земной жизни человека. В трактовке гуманистов человек предстанет как существо без заранее данной ему сущности: он может стать святым или совсем оскотиниться, как пожелает, но в любом случае создает свою сущность по собственной воле. Назначение человека быть свободным, творцом самого себя, что не отрицает ни его причастность к природе, ни причастности к Богу, но открывает между ними еще одно «серединное царство» - царство самого человека (получившее впоследствии название культуры). В границах этого царства человек предстает не как представитель той или иной социальной группы (крестьянин, ремесленник, священник, рыцарь и пр.), а как индивид, свободно избирающий свой жизненный путь. Гуманизм утверждал право человека быть самим собой, автономным существом, достоинство которого заключено лишь в том мастерстве (virtuoso), с каким он выражает себя в своем творчестве.

Поскольку человек в гуманистической перспективе есть особая субстанция, границы которой задаются не природой и не Богом, а им самим, постольку он предстает здесь как самоопределяющееся существо, или, говоря философским языком, как субъект, заключающий в себе причину собственного существования. Хотя в классической философии Нового времени природа человеческой субъективности получит разное толкование, в любом случае она включала в себя теоретическую (познавательную) и прак- 
Научные труды Московского гуманитарного университета 2018 № 2

тическую способности человека, традиционно представленные логикой и этикой. Кант добавит к ним эстетику, очертив тем самым все известное классике пространство человеческой свободы (и, следовательно, культуры). Но чем это пространство отличается от того, которое принято называть природой и которое целиком находится в ведении науки?

Свободу, как и природу, нельзя мыслить вне связи с какой-то детер минацией, т. е. как целиком беспредпосылочное действие. Тогда это не свобода, а произвол («что хочу, то и ворочу»). Уже Аристотель, как известно, различал действующую и финальную, или целевую («causa finalis»), причины. Создавая, какое-то произведение, мы являемся его действующей причиной, но если оно создается нами с какой-то целью, мы оказываемся его целевой причиной. Действие согласно цели и было впоследствии осознано как свободное действие. С возникновением естествознания Нового времени, исключившего из природы все цели, свободу стали отождествлять не с природой, а с культурой. Согласно знаменитому определению культуры, данному Кантом, «способность действовать согласно любой цели (т. е. в свободе) - это культура».

Но если свобода есть действие «согласно любой цели», откуда берутся эти цели? Они могут задаваться чувственной природой индивида, его желаниями и потребностями. В этом случае он действует тоже как свободное существо, но его свобода приходит здесь в столкновение со свободой других. Чтобы избежать состояния конфронтации и вражды, человек, по мысли Канта, должен руководствоваться целью самого разума, свободной от всякой чувственной заинтересованности. Такой целью является для человека его моральный долг, как он формулируется категорическим императивом.

В любом случае классическая философия Нового времени приравняла свободу человека к его способности мыслить и действовать разумно, согласно разуму, как она его понимала. Ее потому и называют философией разума. В гегелевской философии разум предстал как движение мысли от ее изначальной к заключительной фазе, на которой

все индивидуальное и особенное полностью растворяется в обезличенном царстве абсолютной идеи, не оставляющей никакого свободного пространства для личной автономии. Тогда и встал вопрос о том, как возможна индивидуальная свобода в мире научной рациональности. Может ли свобода подобно природе стать предметом научного анализа? Если да, то необходимость в философии отпадает сама собой. Обратив все в науку, философия может теперь удалиться на покой. А может свобода вообще лишь заблуждение нашего ума, простая аберрация сознания, мысленная иллюзия, которой нет места в научно познанном и рационально сконструированном мире? Не приведет ли научный прогресс у отказу человека от 
индивидуальной свободы? Подобные вопросы и вышли на первый план в постклассический период.

Новое время, действительно, внесло в понимание свободы определенные коррективы. Если греки понимали свободу как независимость от материального труда и домашнего хозяйства, а несвободу - как власть главы семейства над домочадцами, слугами и рабами, то теперь свободу станут отождествлять с частной, приватной жизнью в границах своего дела, а несвободу - с властью государства, которую по возможности нужно ограничить. Частное, ставшее общественным, возвестит о рождении общества в современном смысле слова. Теперь свободным будут считать того, кто владеет частной собственностью, занимается собственным бизнесом. По словам Милтона Фридмана, «Сущность капитализма - частная собственность, и она является источником человеческой свободы» (Фридман, 2006: 12). Без экономической свободы нет и политической свободы. «С одной стороны, экономическая свобода сама по себе есть часть свободы в широком смысле. Поэтому экономическая свобода является самоцелью. С другой стороны, экономическая свобода - это необходимое средство к достижению политической свободы» (там же: 31). Получается, что источник несвободы заключен в государстве, тогда как вся сфера производственно-экономической деятельности и есть «царство свободы» ${ }^{1}$.

Перенос центра тяжести в устроении общества из политической в экономическую сферу сказался и на самосознании этой эпохи. Главное в нем теперь - это победа времени над вечностью. Время, ставшее деньгами («время - деньги», скажет Франклин), возвестит о рождении мира, в котором нет места вечному и абсолютному. По словам Мишеля Фуко, это есть «век Истории». Здесь время с его текучестью и подвижностью окончательно вытеснит из сознания всякую отсылку к вечным сущностям и субстанциям - в их религиозном или метафизическом истолковании. Все трансцендентное утрачивает свою силу².

История, согласно Фуко, есть всегда история конечного человека, живущего под постоянной угрозой смерти (от голода или других напастей).

\footnotetext{
${ }^{1}$ Напомню, что для Маркса «царство свободы» располагается «по ту сторону материального производства», т. е. в полном соответствии с греческими представлениями. ${ }^{2}$ По словам К. Маркса, «Все эти трансцендентные профессии, искони пользовавшиеся почетом, - государь, судьи, офицеры, попы и т. д., - вся совокупность порожденных ими старых идеологических сословий, все принадлежащие к этим сословиям ученые, магистры и попы... экономически приравниваются к толпе собственных лакеев и шутов буржуазии, которые содержатся ею и представителями праздного богатства - земельными собственниками и праздными капиталистами. Они просто слуги общества, подобно тому как другие - их слуги. Они живут на продукт труда других людей. Поэтому их число должно быть сокращено до неизбежного минимума».
} 
Научные труды Московского гуманитарного университета 2018 № 2

Преодолеть свою конечность или как-то ослабить ее человек может двумя путями - либо замедлив время, как-то приостановив его, превратив в бесконечно длящееся настоящее, либо как-то «выскочив» из него. То и другое означает «конец истории». Первое решение - «пессимистическое» - принадлежит, как считает Фуко, Рикардо, второе - «революционное» - Марксу. В итоге оба впадают в утопию, т.е. помещают человека туда, где нет уже никакого времени.

Избавиться от утопии, отрицающей историю, по мнению Фуко, можно только ценой «смерти человека» как познавательной «эпистемы», что означает переход к новой - не антропологической, а лингвистической - «эпистеме» с ее представлением о языке как формально структурированной системе. Возникает совершенно новая дискурсивная практика, в которой человек исчезает, испаряется в безличных языковых конструкциях, а сама история предстает как всего лишь «археология знания». Правда, Фуко называет такое предположение не ответом, а только вопросом, но, в любом случае, для него несомненно, что человек есть «изобретение недавнее», продукт одной из возможных «диспозиций знания» и потому его конец неизбежен. Впоследствии он попытается представить историю как историю власти, меняющей во времени лишь свои обличия и способы предъявления. Вывод вполне логичный: в истории, не знающей вечности, нет места и человеку с его свободой.

Время, лишенное связи с вечностью, есть безличное время социальных изменений с разной степенью длительности. Соответственно его трактуют как время трансформации социальных институтов и структур, т. е. как время жизни вещей, но не людей. Время же человеческой жизни, как в язычестве, опять измеряется жизнью его тела, а не духа, т. е. безотносительно к чему-то вечному и бессмертному. «Сегодня, — по словам Зигмунта Баумана, - все построенные в культуре мосты, соединяющие человека с вечностью, полностью разрушены. Путь в вечность перекрыт для современного человека и ему остается лишь сосредоточиться на своем телесном существовании, найти в нем смысл и ценность (Бауман, 2002: 313). Забота о теле становится главной заботой человека, отодвигая на второй план все остальные его интересы и помыслы ${ }^{1}$. Наиболее значимым и более всего переживаемым событием такой жизни становится смерть. Во всем видят теперь неизбежную печать смерти, признак надвигающегося конца, приближающейся ги-

\footnotetext{
${ }^{1}$ Как пишет Бауман, «коль скоро телесное существование остается единственно значимой вещью, невозможно представить себе нечто, более ценное и достойное заботы. Наше время отмечено чрезмерным вниманием к телу. Тело представляется крепостью, окруженной хитрыми и тайными врагами. Оно должно быть защищаемо ежедневно...» (Бауман, 2002: 313).
} 
бели. Смерть становится главной темой и художественного творчества. По словам Баумана, «самые известные художественные артефакты наших дней высмеивают бессмертие или обнаруживают к нему полное равнодушие... Исчезновение и умирание - вот что выставляют ныне в художественных музеях» (там же: 314 ).

Но что в такой ситуации делать философу? Ведь время, подлежащее чисто количественному счету, измеряемое часами, днями, неделями и пр., как уже было ясно грекам. Есть время не столько свободы человека, сколько его физически конечной жизни, подчиненной целиком заботе о собственном выживании. Труд в материальном производстве или на службе в офисе и фирме, измеряемый временем, стал предельным выражением несвободы человека в современном обществе, правда, не личной несвободы (как в рабстве или крепостничестве), а вещной, предполагающей продажу в наем своей рабочей силы. Работа по найму есть что угодно, но только не свобода. Время такого труда получило название рабочего времени. В обществе, где «основной мерой общественного богатства» служит рабочее время, человек чувствует себя свободным лишь за пределами своей работы, в кругу друзей, знакомых или близких. Для многих и сегодня время, проведенное в семейном кругу, посвященное домашним делам и заботам, намного предпочтительнее времени, которое они проводят на производстве или на службе. В первом они живут, во втором - только зарабатывают на жизнь. И не так уж не прав был Маркс, сказавший как-то, что в современном обществе человек чувствует себя человеком только при исполнении своих животных функций - в еде, питье, процессе размножения, тогда как в самом обществе он чувствует себя животным.

Следует, видимо, согласиться с Марксом и в том, что общество, в котором рабочее время является основным временем общественной жизни для большинства людей, нельзя считать полностью свободным. Но тогда прогрессом, видимо, будет сокращение рабочего времени «до минимума» и как следствие увеличение свободного времени. Под последним следует понимать не время свободы от труда, а время свободного труда, труда по призванию, соответствующего личным дарованиям, способностям и талантам человека. Оно превращает индивида в «иного субъекта» по сравнению с непосредственным трудом рабочего, в качестве кого он и входит затем в процесс производства.

Хотя в современном обществе свободное время уже давно стало общедоступным благом, для большинства работающих людей оно еще не обрело значения основного времени их общественной жизни и ценится ими как время, свободное от общественно-необходимого труда, целиком заполненное домашним заботам, отдыху и досугу. Способствуя росту консюмериз- 
Научные труды Московского гуманитарного университета 2018 № 2

ма и голого потребительства, на что работает вся современная индустрия досуга. Такое время летит с ускоренной быстротой, ни на чем особенно не задерживаясь, ничего не оставляя в памяти, никуда не устремляясь. Оно подобно дурной бесконечности, как бы кружащейся в бесконечном повторе одного и того же.

Вырваться за пределы такого кружения, можно лишь превратив свободное время в «основную меру общественного богатства» (т. е. чем его больше в обществе, тем оно богаче). Мерой богатства свободное время становится как время не только личного потребления и досуга, но прежде всего самого труда, создающего это богатство. Тогда таким богатством является сам человек во всей целостности и всесторонности своего общественного бытия. Свободное время и есть время производства человеком себя как «основного капитала». Оно позволяет ему быть тем, кем он является по своей природе, вступать в общение со всеми, с кем он пожелает, будь то современники, предки или потомки, т. е. позволяет ему жить в пространстве не только в пространстве отпущенного ему времени его физической жизни, но и всей человеческой истории. Такая жизнь и подобна жизни в вечности, но только на этом, а не на том свете.

Подобное понимание свободы отличается от ее понимания в классической философии. Начиная с греков, философы искали свободу за пределами времени, в царстве вечных истин, над которыми время не властно. С победой времени над вечностью в ее религиозном и метафизическом истолковании, о чем уже говорилось выше, ее будут искать уже не на небесах и не в мире сверхчувственных и умопостигаемых субстанций, а в реальном времени человеческой жизни. Под свободой здесь станут понимать, прежде всего, политические и экономические свободы частного лица, живущего в гражданском обществе. Однако, эти свободы, как станет ясно чуть позже, не исчерпывают собой всей свободы, доступной человека как свободной индивидуальности. Следует отличать индивидуальное от частного. За различением этих понятий скрывается разное понимание человеческой природы в гуманизме, идущем из эпохи Возрождения, и либерализме, имеющим своим истоком эпоху Просвещения. Как индивидуальность человек равен не части (частный собственник или частичный рабочий), полученной путем дележа собственности и труда, а целому, как оно предстает за пределами их общественного разделения. Так, людей культуры - мыслителей, художников, ученых - никак не назовешь частниками. Каждый из них наделен собственным лицом и неповторимой индивидуальностью. Свобода не частного лица, а человека со своей индивидуальностью, творчески реализующего себя в процессе самосозидания - вот предмет интереса современной философии в ее функции самосознания. 
Человек - не просто биологическая особь, но индивидуальность, которую нельзя ни повторить, ни заменить кем-то другим. В этом смысле он - однократное существо, не воспроизводимое во времени. В отличие от видового многообразия растительного и животного мира таксономической единицей человеческого рода является все же не вид, а индивид во всей уникальности и неповторимости его бытия. Именно как индивидуальность человек нуждается во времени, которое позволяет ему не просто выжить, но прожить собственную и ни на кого не похожую жизнь. Такое время измеряется не количеством прожитых лет, не просто дтами рождения и смерти, а их качеством - тем, что им лично пережито, понято и сделано. Как индивидуальность человек существует не в физически конечном, а в бесконечно длящемся времени (Пушкин - всегда и везде Пушкин, второго Пушкина быть не может), которое не поддается простому количественному счету: за одно и то же число лет можно прожить самые разные жизни. Жизнь одного человека нельзя заменить жизнью другого человека, каждая жизнь сохраняется (хотя бы в памяти потомства) на все последующие времена. Не всем, конечно, дано прожить такую жтзнь, но именно она отличает человеческую жизнь от любой другой.

Тем самым в наше сознание входит то, что называют «вечностью» или «бессмертием» и без чего наша жизнь утратила бы для нас всякую ценность ${ }^{1}$. Наша связь с вечностью и осознается нами как предельно доступная нам свобода. Подобная связь позволяет человеку выйти за пределы своей конечной жизни, преодолеть «плен времени», сохранить себя, свою индивидуальность в бесконечной череде сменяющих друг друга явлений и событий. Функцию такой связи (или «моста», по выражению Зигмунта Баумана) между быстротекущим временем человеческой жизни и вечностью как раз и выполняет культура, а способ включения человека в эту связь философы ищут теперь уже не за пределами времени, а в самом времени, которое потому и называется свободным. В качестве самосознания современного человека, живущего в свободном времени, философия и предстает сегодня как особая форма сознания наряду с наукой.

\footnotetext{
${ }^{1}$ Вот как ту же мысль формулирует современный социолог: «Осознание неизбежности смерти могло бы с легкостью лишить нашу жизнь ее ценности, если бы понимание хрупкости и конечности жизни не наделяло колоссальной ценностью долговечность и бесконечность». И далее: «Осознание мимолетности жизни делает ценной только вечную длительность. Она утверждает ценность нашей жизни косвенно, порождая понимание того, что сколь бы коротка не была наша жизнь, промежуток времени между рождением и смертью - наш единственный шанс постичь трансцендентное, обрести опору в вечности» (Бауман, 2002: 300).
} 


\section{СПИСОК ЛИТЕРАТУРЫ}

Арендт, X. (2000) Vita activa, или о деятельной жизни. СПб.: Алетейя.

Бауман, 3. (2002) Индивидуализированное общество. М.: Логос.

Бауман, 3. (2006) Свобода. М.: Новое издательство.

Вернан, Ж.-П. (1998) Происхождение древнегреческой мысли. М. : Прогресс.

Гайденко, П. П. (2006) Время, длительность, вечность. М.: Прогресс-Традиция.

Кожев, А. (2003) Введение в чтение Гегеля. Лекции по Феноменологии духа, читавшиеся с 1933 по 1939 гг. в Высшей практической школе. СПб. : Наука. 791 c.

Ницше, Ф. (1994) Философия в трагическую эпоху. M.: REEL-book.

Фридман, М. (2006) Капитализм и свобода. М.: Новое издательство.

Хайдеггер, М. (1991) Разговор на проселочной дороге. М.: Высшая школа.

Шпенглер, О. (1993) Закат Европы. Очерки морфологии мировой истории. Т. 1. Гештальт и действительность. М.: Мысль.

Дата поступления: 12.12.2017 2.

Межуев Вадим Михайлович - доктор философских наук, главный научный сотрудник Института философии РАН. Адрес: 109240, Россия, г. Москва, ул. Гончарная, д. 12, стр. 1. Эл. адрес: rushist@iph.ras.ru

Mezhuev Vadim Mikhailovich, Doctor of Philosophy, Chief Research Fellow, Institute of Philosophy, Russian Academy of Sciences. Postal address: 12, Bldg. 1, Goncharnaya St., Moscow, Russian Federation, 109240. E-mail: rushist@iph.ras.ru

\section{Для цитирования:}

Межуев В. М. Философия как самосознание свободы [Электронный ресурс] // Научные труды Московского гуманитарного университета. 2018. №2. URL: http://journals.mosgu.ru/trudy/article/view/688 (дата обращения: дд.мм.гг.). DOI: 10.17805/trudy.2018.2.1 